\title{
THE RELATION BETWEEN CARDIAC SIZE AND CARDIAC OUTPUT PER MINUTE FOLLOWING THE ADMINISTRA- TION OF DIGITALIS IN DOGS IN WHICH THE HEART IS ENLARGED
}

BY ALFRED E. COHN AND HAROLD J. STEWART

(From the Hospital of The Rockefeller Institute for Medical Research, New York)

(Received for publication June 25, 1928)

In the preceding paper (Cohn and Stewart, 1928) we have described the effect of digitalis on the cardiac output, cardiac size and cardiac contraction of normal dogs. The cardiac output that obtains in a given dog at a given instant we found is the net result of the working of two distinct, in a sense, opposing actions: first, cardiac size is decreased, and so tends to decrease cardiac output; and second, ventricular contraction is increased, and so tends to increase it. Next, we desired to learn again in dogs whether the same net results are characteristic of the behavior of abnormal, enlarged hearts. We soon found that in the absence of heart failure, no significant difference between the two is to be detected; but we are still without information on the situation in which this added defect of heart failure exists.

For several years we have been concerned with finding a method which would establish a state in dogs comparable to heart failure in man. One of the methods has consisted in the attempt to bring about this state by rendering the mitral valve insufficient. We have for this reason in our possession a number of dogs in which defects of the mitral valve have been made by operation and in which enlarged hearts have in consequence developed. They show no signs however of heart failure. To these dogs we have given digitalis just as to the normal dogs. Estimations of cardiac output, as well as $\mathrm{x}$-ray photographs of cardiac size and of ventricular excursions have been made, just as in the case of the normal dogs. 


\section{MATERIAL}

The dogs which were studied were operated on $2 \frac{1}{6}$ to $4 \frac{1}{12}$ years ago. Evidence of the lesions which were then created were still present at the time of these experiments (table 1). Complete data concerning the operations in these animals will be published later (Stewart). A brief description only of the method used in operating on the valves need be given. Under ether and under aseptic conditions the left auricular appendage was exposed and incised. A cardioscope ${ }^{1}$ was then inserted through this opening and placed so that the leaflets of

TABLE 1

Enlargement of the heart following induction of artificial mitral insufficiency in dogs

\begin{tabular}{|c|c|c|c|c|}
\hline Dog number & $\begin{array}{l}\text { Area of heart* } \\
\text { before operation }\end{array}$ & $\begin{array}{l}\text { Area of heart* } \\
\text { after operation }\end{array}$ & $\begin{array}{l}\text { Time since } \\
\text { operation }\end{array}$ & $\begin{array}{l}\text { Increase in heart } \\
\text { area }\end{array}$ \\
\hline & $s q . \mathrm{cm}$, & $s q . \mathrm{cm}$ & years & per cent \\
\hline 155 & 56.1 & 66.1 & $2 \frac{1}{2}$ & 18 \\
\hline \multirow[t]{2}{*}{158} & \multirow[t]{2}{*}{46.4} & 84.3 & $2 \frac{1}{2}$ & 82 \\
\hline & & 90.2 & $3 \frac{1}{3}$ & 94 \\
\hline \multirow[t]{2}{*}{161} & \multirow[t]{2}{*}{46.0} & 71.4 & $2 \frac{1}{2}$ & 55 \\
\hline & & 81.2 & $3 \frac{1}{4}$ & 77 \\
\hline \multirow[t]{2}{*}{162} & \multirow[t]{2}{*}{55.0} & 65.8 & $2 \frac{1}{2}$ & 20 \\
\hline & & 66.9 & $3 \frac{1}{6}$ & 22 \\
\hline 171 & 50.3 & 62.3 & $2 \frac{1}{6}$ & 24 \\
\hline 90 & 43.0 & 45.3 & $4 \frac{1}{1} \frac{1}{2}$ & 5 \\
\hline
\end{tabular}

* The $x$-ray photographs were made at a distance of 2 meters.

the mitral valve were brought into view. The leaflet could then be cut under direct vision. Development of a marked systolic thrill was

1 The cardioscope which we used was designed with the assistance of Mr. R. Wappler, and was made for us by the Wappler Electric Company, Long Island City, New York. The idea of cutting the valves of the heart under direct vision was suggested to us by the preliminary report of Allen and Graham (1922). As complete data for the construction of their instrument was not available at the time, we devised this new instrument. The optical system is similar to that used in cystoscopes. We are much indebted to Doctors Graham and Allen for valuable aid in learning their methods and desire to express our thanks to them for their courtesy. 
regarded as evidence that the operation had succeeded. The dogs completely recovered within 10 days to two weeks. The hearts began to increase in size after varying intervals of time. A loud systolic murmur persisted in each of the dogs. The dogs studied for the present purpose were in good health. Through preliminary training they were accustomed to laboratory procedures and were not disturbed by them.

\section{METHODS}

The technique of the experiments was, except for slight details, identical with that reported in the preceding paper. The cardiac output was estimated according to the principle of Fick (1870) (Cohn and Stewart, 1928). Arterial blood was drawn from a femoral artery. In some of the dogs the right external jugular vein had been punctured so often for inserting a cannula into the right ventricle to obtain samples of mixed venous blood (Stewart, 1925) that it was no longer possible to locate the vessel. Contrary to expectation, we were surprised to find that the left external jugular vein could be used for this purpose with equal, perhaps with greater, facility. Either the left external jugular vein itself or one of its branches could be made to serve. This observation extends the usefulness of this method of obtaining samples of mixed venous blood. The veins as usual were isolated with sterile precautions under novocain anesthesia. Adequate asepsis could be maintained by very simple measures.

As in studying normal dogs, the ventricular excursions were recorded by the method of moving x-ray films. The size of the heart was measured in stationary $\mathbf{x}$-ray photographs taken just before securing the moving $x$-ray films. The observations were made in the following order: first, the $\mathrm{x}$-ray photographs, second, estimations of the cardiac output and last, electrocardiograms.

Tincture of digitalis (Upsher Smith) equivalent to 25 to 30 per cent of the calculated lethal dose was injected intravenously as in the case of the normal dogs. In two experiments the dogs moved during injection so that part of the dose was given subcutaneously (table 2, dogs 90 and 161). The results in these two do not differ from those in which the whole dose was given intravenously. In two instances digifoline (Ciba) was given. Of this preparation $0.5 \mathrm{cc}$. was injected intravenously per kilogram of body weight. 
TAB

Effect of digitalis on cardiac output, cardiac size and ventricula,

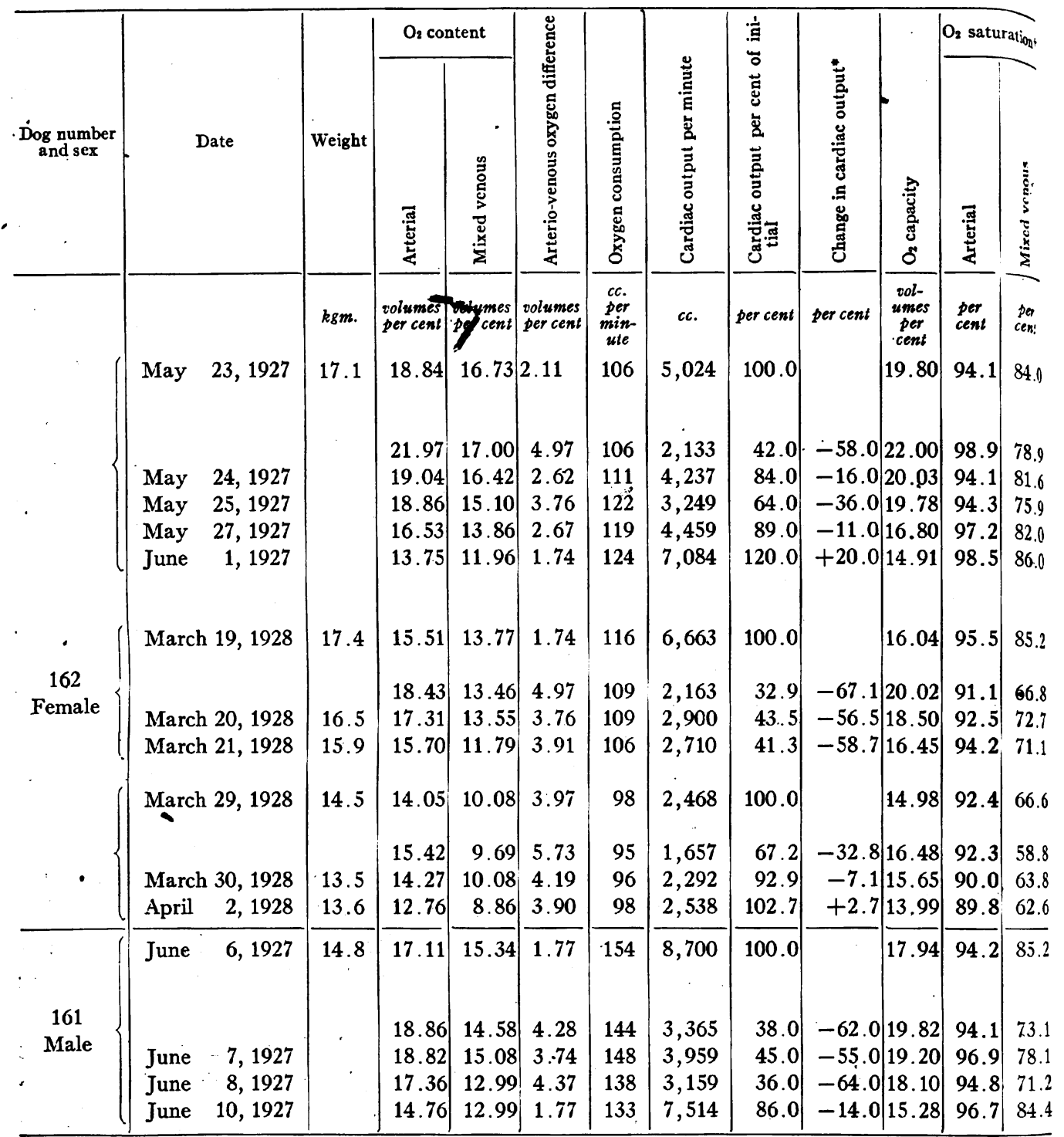

* In this column, + indicates increase, and - decrease.

$\dagger$ Before calculating the oxygen saturations 0.2 and 0.1 volume per cent (the amount of oxygen in physical solution) were subtracted from the arterial and mixed venous oxygen contents respectively.

$\S$ Tincture of digitalis unless otherwise indicated.

$\|$ N.R = normal rhythm; A.F. = auricular fibrillation; V.P.C. = ventricular premature contractions; A.P.C. = auricular premature contractions; Vent. Par. Tach. = ventricular paroxysmal tachycardia; I-H.B. = incomplete heart block; $+\mathrm{P}-\mathrm{R}=$ conduction time increased. 
LE 2 contraction (excursion) in dogs in which the heart is enlarged

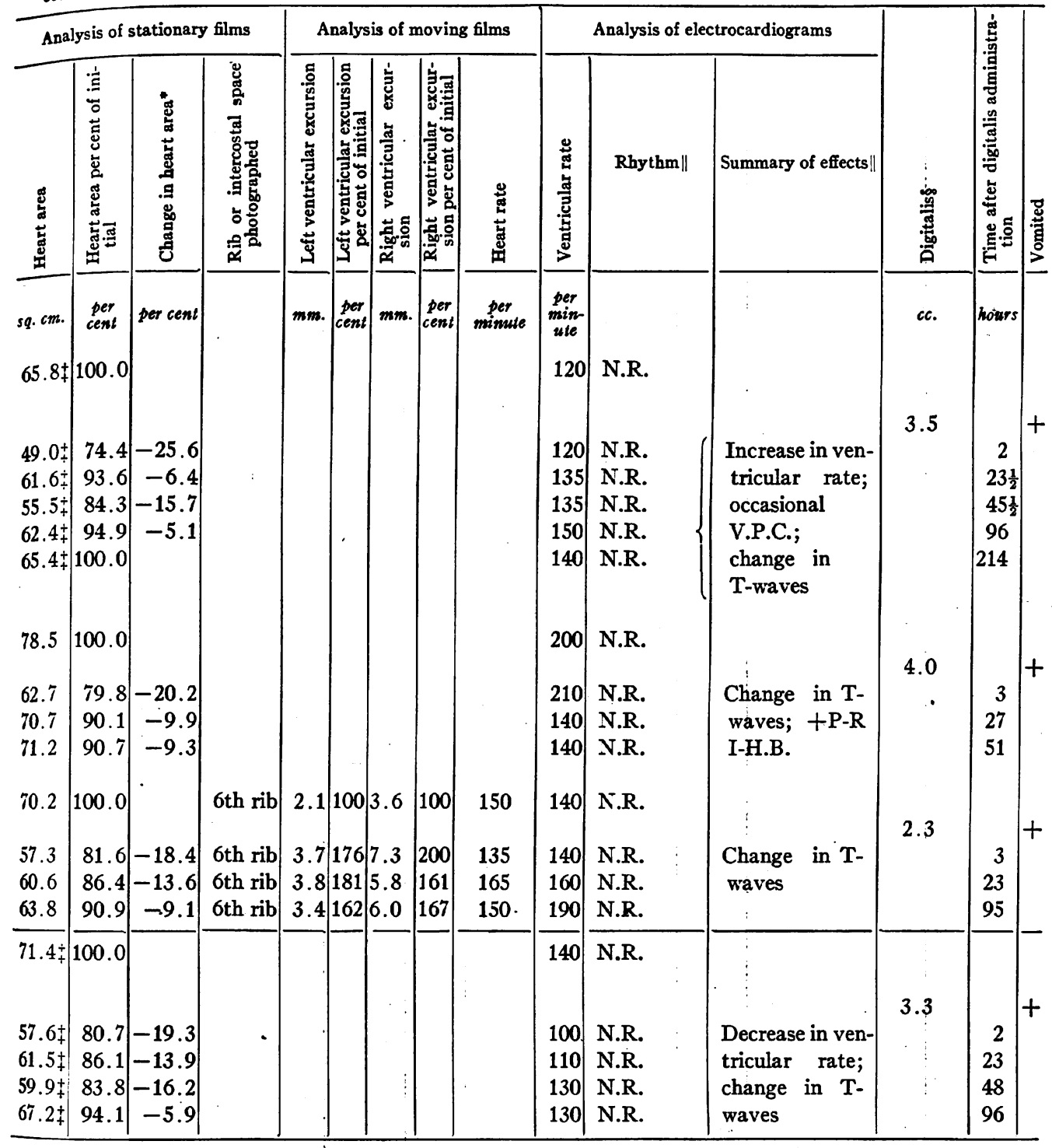

$\ddagger$ The $x$-ray photographs from which these measurements were made were taken at a distance of 2 meters; all others at a distance of 34 inches.

$1.0 \mathrm{cc}$. of this was given subcutaneously.

** $2.6 \mathrm{cc}$. of this was given subcutaneously. 
TABLE 2

\begin{tabular}{|c|c|c|c|c|c|c|c|c|c|c|c|c|}
\hline \multirow[b]{2}{*}{$\begin{array}{l}\text { Dog number } \\
\text { and sex }\end{array}$} & \multirow[b]{2}{*}{ Date } & \multirow[b]{2}{*}{ Weight } & \multicolumn{2}{|c|}{$\mathrm{O}_{2}$ content } & \multirow{2}{*}{ 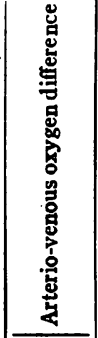 } & \multirow[b]{2}{*}{ 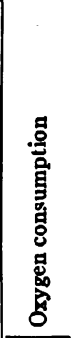 } & \multirow[b]{2}{*}{ 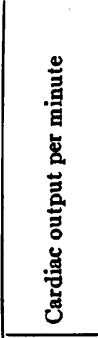 } & \multirow{2}{*}{ 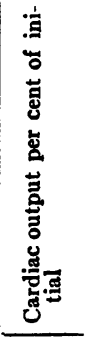 } & \multirow[b]{2}{*}{ 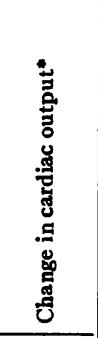 } & \multirow[b]{2}{*}{ 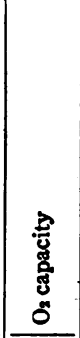 } & \multicolumn{2}{|c|}{$\mathrm{O}_{2}$ saturation $\uparrow$} \\
\hline & & & 恶 & 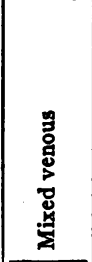 & & & & & & & $\begin{array}{l}\overrightarrow{5} \\
\stackrel{5}{5} \\
\end{array}$ & 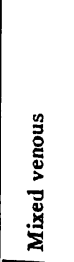 \\
\hline \multirow{5}{*}{$\begin{array}{c}{ }^{161} \\
\text { Male } \\
\text { (con- } \\
\text { tinued) }\end{array}$} & \multirow[b]{2}{*}{ March 27, 1928} & kgm. & $\begin{array}{l}\text { volumes } \\
\text { per cent }\end{array}$ & $\begin{array}{l}\text { oolumes } \\
\text { per cent }\end{array}$ & $\begin{array}{l}\text { volumes } \\
\text { per cent }\end{array}$ & $\begin{array}{c}c c . \\
\text { per } \\
\text { min- } \\
\text { ute }\end{array}$ & $c c$. & per cent & per cent & $\begin{array}{c}\text { ool- } \\
\text { umes } \\
\text { per } \\
\text { cent }\end{array}$ & $\begin{array}{l}\text { per } \\
\text { cent }\end{array}$ & $\begin{array}{c}\text { per } \\
\text { cent }\end{array}$ \\
\hline & & 13.9 & 17.67 & 15.10 & 2.57 & 104 & 4,048 & 100.0 & & 18.95 & 92.2 & 79.2 \\
\hline & \multirow{3}{*}{$\begin{array}{l}\text { March 28, } 1928 \\
\text { March 31, } 1928\end{array}$} & & 19.91 & 15.96 & 3.95 & 109 & 2,760 & 68.2 & -31.8 & 21.70 & 90.9 & 73.1 \\
\hline & & 13.0 & 20.59 & 14.15 & 6.44 & 105 & 1,630 & 40.3 & -59.7 & 22.40 & 91.0 & 62.3 \\
\hline & & 13.0 & 17.64 & 12.97 & 4.67 & 108 & 2,313 & 57.2 & -42.8 & 18.55 & 94.0 & 69.4 \\
\hline \multirow{13}{*}{$\begin{array}{c}158 \\
\text { Male }\end{array}$} & May 31,1927 & \multirow[t]{4}{*}{20.2} & 20.32 & 19.04 & 1.28 & 128 & 10,000 & 100.0 & & 21.17 & 95.0 & 89.5 \\
\hline & & & 19.08 & 14.00 & 5.08 & 126 & 2,480 & 25.0 & -75.0 & 19.85 & 95.8 & 70.1 \\
\hline & June $\quad 1,1927$ & & 20.34 & 16.80 & 3.52 & 136 & 3,841 & 38.0 & -62.0 & 21.59 & $94: 2$ & 77.8 \\
\hline & June 2,1927 & & 18.77 & 16.73 & 2.04 & 142 & 6,960 & 70.0 & -30.0 & 19.67 & 94.4 & 84.6 \\
\hline & June $\quad 9,1927$ & 19.2 & \multirow{2}{*}{$\begin{array}{l}16.91 \\
20.41\end{array}$} & 15.39 & 1.52 & 130 & 8,553 & 100.0 & \multicolumn{2}{|r|}{17.45} & 95.7 & 87.6 \\
\hline & \multirow{3}{*}{$\begin{array}{ll}\text { June } & 10,1927 \\
\text { June } & 11,1927\end{array}$} & & & 15.37 & 5.04 & 131 & 2,600 & 35.0 & -65.0 & 21.64 & 93.3 & 70.6 \\
\hline & & & 19.44 & 14.58 & 4.86 & 111 & 2,284 & 27.0 & -73.0 & 21.21 & 90.7 & 68.3 \\
\hline & & & 16.66 & 13.73 & 2.93 & 112 & 3,823 & 45.0 & -55.0 & 18.08 & 91.0 & 75.4 \\
\hline & March 22, 1928 & 20.3 & 20.60 & 18.66 & 1.94 & 126 & 6,500 & 100.0 & & 21.38 & 95.5 & 86.9 \\
\hline & & & 22.78 & 19.30 & 3.48 & 119 & 3,418 & 52.6 & -47.4 & 24.47 & 92.3 & 78.5 \\
\hline & March 23, 1928 & 18.3 & 23.20 & 17.90 & 5.30 & 126 & 2,370 & 36.5 & -63.5 & 24.07 & 95.6 & 74.0 \\
\hline & March 24, 1928 & 17.9 & 21.27 & 18.34 & 2.93 & 132 & 4,510 & 69.4 & -30.6 & 22.88 & 92.1 & 79.7 \\
\hline & March 26, 1928 & 18.5 & 19.02 & $\mid 14.86$ & 4.16 & 123 & 2,960 & 45.6 & -55.4 & 20.37 & 92.4 & 72.5 \\
\hline
\end{tabular}




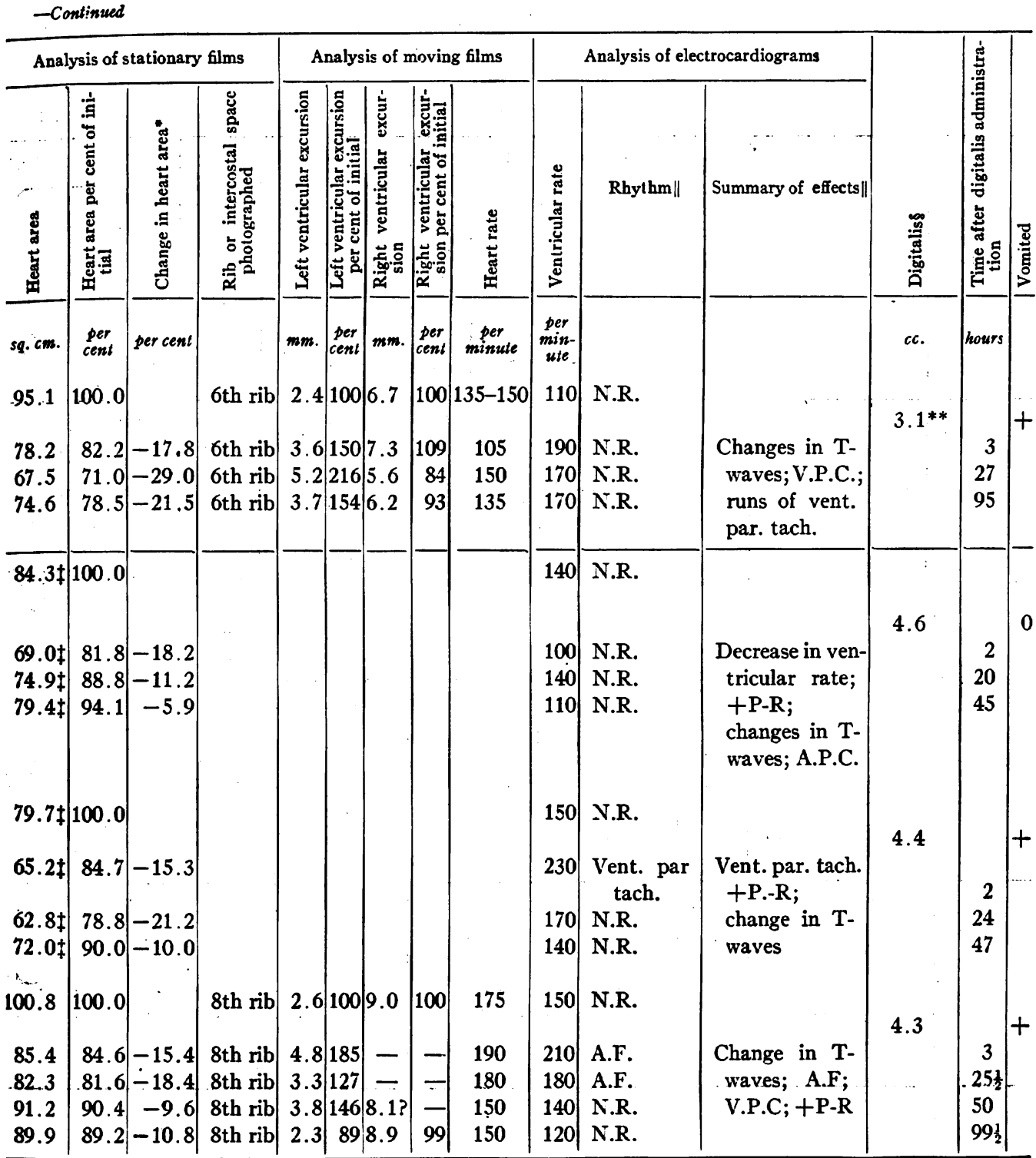


TABLE 2

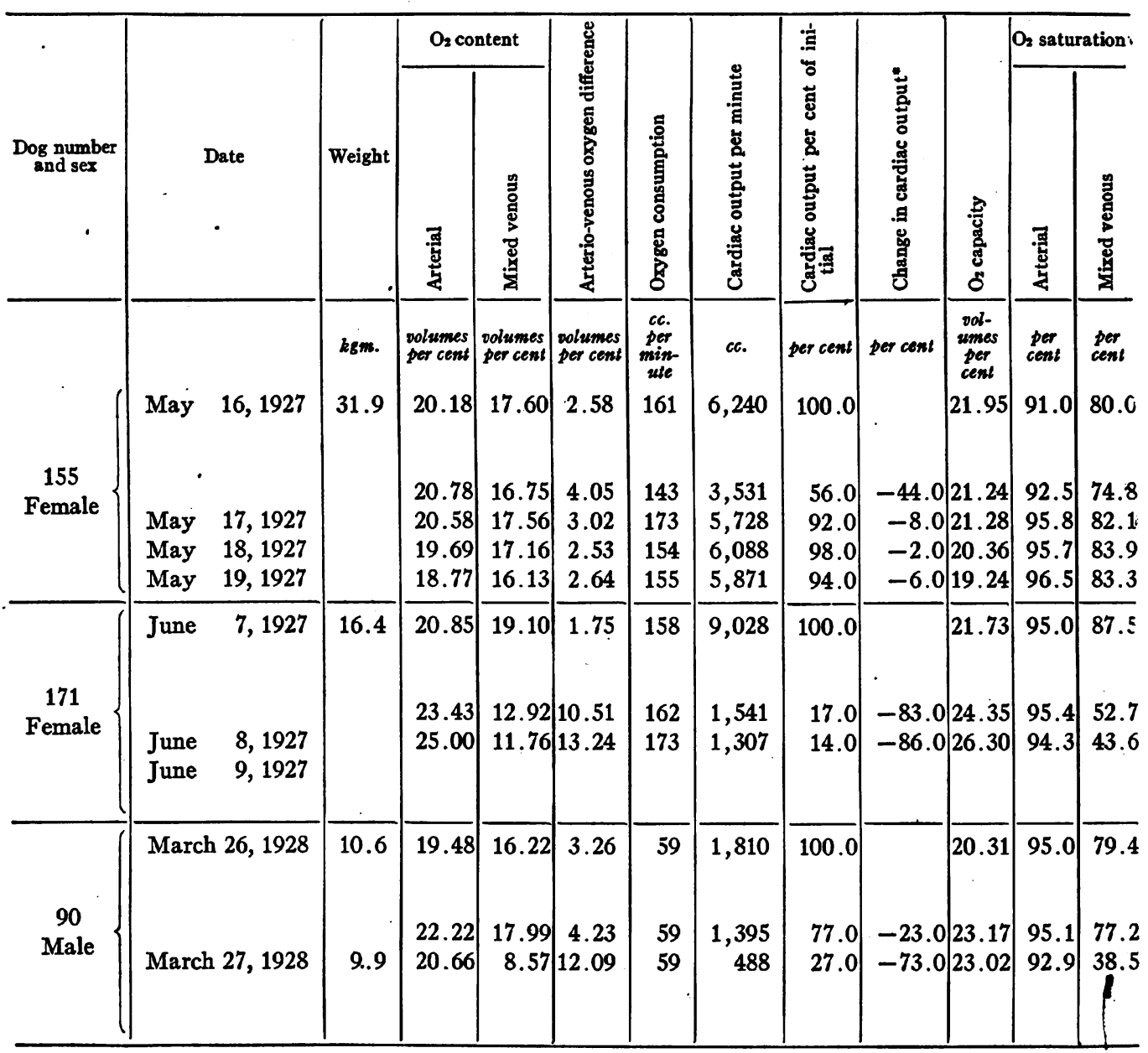




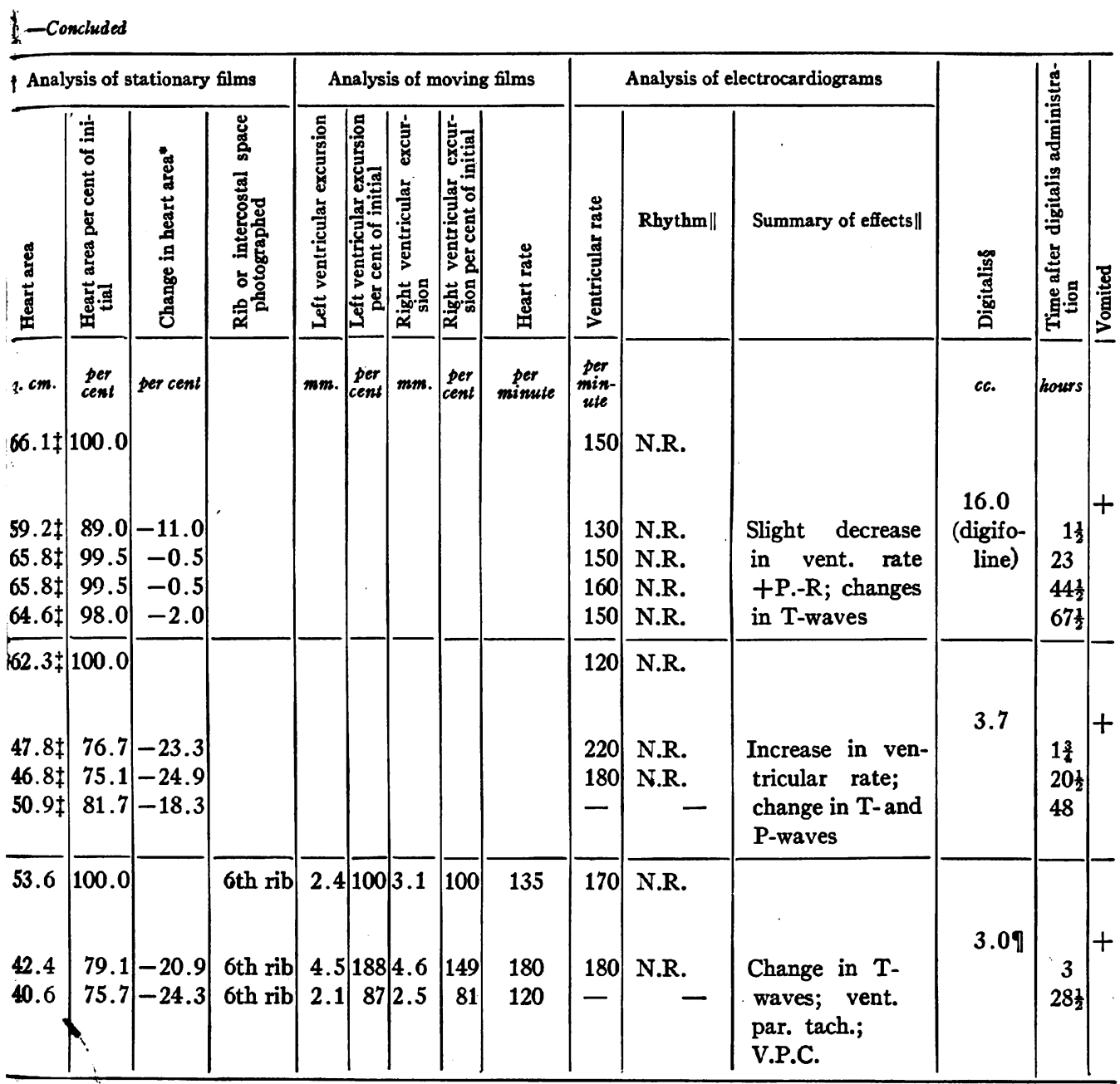




\section{OBSERVATIONS}

Effect of digitalis on cardiac output. Mitral insufficiency was created

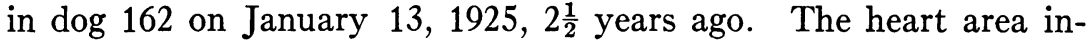
creased 20 per cent during this time, from 55.0 to $65.8 \mathrm{sq} . \mathrm{cm}$. (table 1 ). The cardiac output on May 23, 1927, was 5024 cc. per minute (table 2). Two hours after injection of tincture of digitalis $3.5 \mathrm{cc}$, the output decreased to $2133 \mathrm{cc}$. per minute; 23 hours after, it increased to 4237 cc.; 45 hours after it fell to $3249 \mathrm{cc} ; 81 \frac{1}{2}$ hours after it was $4459 \mathrm{cc}$; and $103 \frac{1}{2}$ hours after, $7084 \mathrm{cc}$. The decrease (58 per cent) in cardiac output was at a maximum 2 hours after digitalis was given. The output returned to normal with slight fluctuations toward the end of the 8th day.

On March 19, 1928, the experiment was repeated $3 \frac{1}{6}$ years after the first operation. The heart had enlarged 22 per cent (table 1). The cardiac output was $6663 \mathrm{cc}$. per minute (table 2). Tincture of digitalis $4.0 \mathrm{cc}$. was then administered intravenously. Three hours later the output fell to $2193 \mathrm{cc}$. but increased the following day to $2900 \mathrm{cc}$. The output had not returned to normal 9 days later and was only 2468 cc. per minute. On March 29, tincture of digitalis 2.3 cc. was again injected intravenously, and was followed by a fall in cardiac output to $1657 \mathrm{cc}$. or 67.2 per cent of the initial measurement, in 3 hours (table 2, fig. 1). At the end of four days the cardiac output returned to $2535 \mathrm{cc}$. or 102.7 per cent of the output at the beginning of this period (March 29, 1928). On three occasions accordingly the administration of digitalis in this dog was followed by decreases in cardiac output.

Mitral insufficiency was created in dog 161 in December 11, 1924, $2 \frac{1}{2}$ years ago. During this time the area of the heart increased 55 per cent from 46.0 to $71.4 \mathrm{sq} . \mathrm{cm}$. (table 1). The cardiac output was estimated on June 6, 1927, and found to be $8700 \mathrm{cc}$. per minute (table 2). Tincture of digitalis $3.3 \mathrm{cc}$. was then given intravenously. When estimated 2 hours later the output was found to have decreased to $3365 \mathrm{cc}$. per minute. The measurement 21 hours after injection rose to 3959 cc.; but after 48 hours it again fell to 3159 cc.; after 96 hours it increased to $7514 \mathrm{cc}$. There was accordingly a decrease of 62 per cent in cardiac output immediately after giving digitalis. At the end of four days the effect had nearly worn off. 
Mitpal insufficiency for $3 \frac{1}{2}$ years.

Heart enlarged 22. per cent over

Per

the initial size.

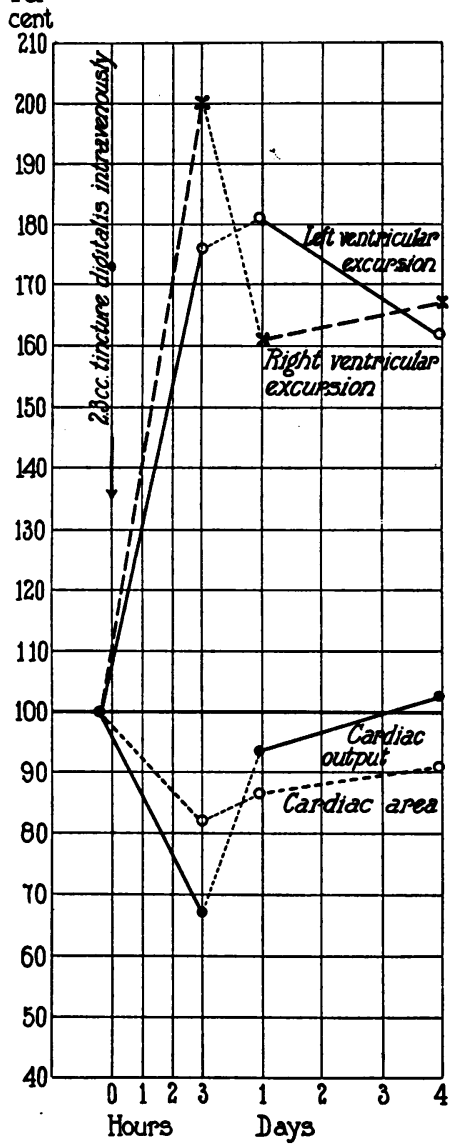

Frg. 1

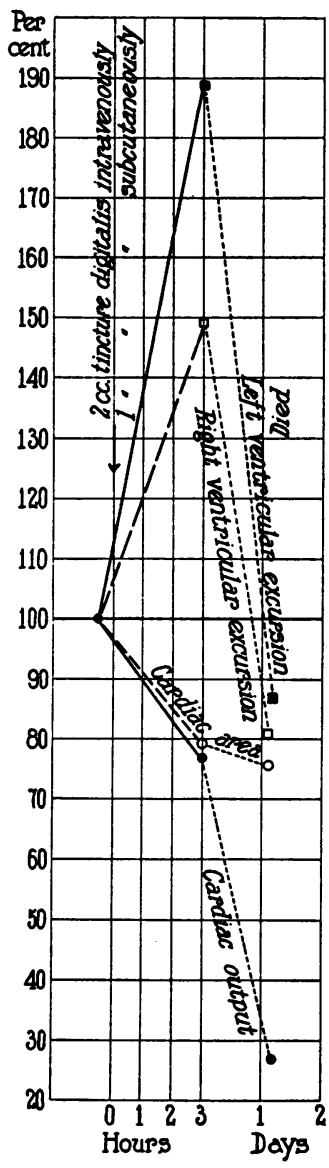

Fig. 2

FIG. 1. In this figure is shown the effect of giving digitalis on cardiac output, cardiac size and excursions of the right and left ventricles in dog 162 . In this instance after the preliminary decrease the cardiac output returned to normal even though the heart was smaller than it was at the beginning. At that time the height of the ventricular excursions continued to be greater than it was in the initial measurements.

FIG. 2. In this figure is shown the effect of giving digitalis on cardiac output, cardiac size and ventricular excursions in dog 90. The dog died about 24 hours after the drug was given. 
The experiment was repeated 9 months later on March 27, 1928. It was now $3 \frac{1}{4}$ years since operation. The heart had increased in size 77 per cent (table 1). The cardiac output was $4048 \mathrm{cc}$. per minute (table 2). Tincture of digitalis $2.6 \mathrm{cc}$. was given intravenously and 0.5 cc. subcutaneously. The output fell 3 hours later to $2760 \mathrm{cc}$. and 24 hours later still further, to $1630 \mathrm{cc}$. It rose to $2313 \mathrm{cc} .4$ days after injection. There was then a maximum fall of 60 per cent in cardiac output followed by return toward normal.

Mitral insufficiency was created in dog 158 on December 2, 1924, $2 \frac{1}{2}$ years ago. The area of the heart increased ( 82 per cent) from 46.4 to $84.3 \mathrm{sq}$. $\mathrm{cm}$. (table 1). The cardiac output on May 31,1927 was 10,000 cc. per minute (table 2). Two hours after the injection of tincture of digitalis $4.6 \mathrm{cc}$. the output fell to $2480 \mathrm{cc}$; 20 hours after, it rose to $3841 \mathrm{cc}$; and 45 hours after, it rose further to $6960 \mathrm{cc}$. A week later it rose still further to $8553 \mathrm{cc}$., nearly to the level existing before digitalis was administered. On June 6,1927, tincture of digitalis $4.4 \mathrm{cc}$. was given again. Two hours later the output decreased to $2600 \mathrm{cc}$. per minute, and 24 hours afterward decreased further to $2284 \mathrm{cc}$. At the end of 47 hours the cardiac output began to increase and was found to be $3823 \mathrm{cc}$. The output decreased then 75 per cent following the administration of digitalis and slowly returned toward normal.

Digitalis was given again 10 months later. Mitral insufficiency had now been established for $3 \frac{1}{3}$ years. During this time the heart area increased 94 per cent from $46.4 \mathrm{sq} . \mathrm{cm}$. to $90.2 \mathrm{sq}$. cm. (table 1). The cardiac output on March 22, 1928 was $6500 \mathrm{cc}$. per minute (table 2). Tincture of digitalis $4.3 \mathrm{cc}$. was injected intravenously. The output fell 3 hours later to $3418 \mathrm{cc}$; 1 day later it fell further to $2370 \mathrm{cc}$; 1 day later still it increased to $4510 \mathrm{cc}$. and 2 days later, that is to say, 4 days after injection it fell again to $2960 \mathrm{cc}$. There was a maximum decrease (64 per cent) in cardiac output 25 hours after the injection of digitalis, followed by a slow return toward normal. On three occasions the same result followed the administration of digitalis; there was always a decrease in cardiac output.

Mitral insufficiency was created in dog 155 on February 25, 1925, $2 \frac{1}{2}$ years ago. After this the dog became pregnant and was delivered of 5 puppies without developing any signs of heart failure. The area 
of the heart increased 18 per cent, from 56.1 to $66.1 \mathrm{sq} . \mathrm{cm}$. (table 1 ). The cardiac output was $6240 \mathrm{cc}$. per minute (table 2). One and one half hours after injection of digifoline $16 \mathrm{cc}$. the output fell to $3631 \mathrm{cc}$; 23 hours afterward it increased to $5728 \mathrm{cc}$.; $44 \frac{1}{2}$ hours afterward still further, to $6088 \mathrm{cc}$.; and $67 \frac{1}{2}$ hours afterward it fell slightly to $5871 \mathrm{cc}$. In summary then, the output decreased 44 per cent, and was followed by a return to normal in 48 hours.

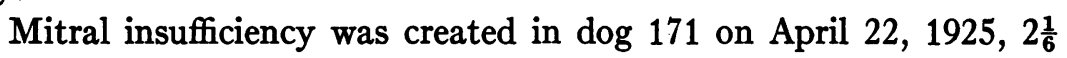
years ago. The area of the heart increased 24 per cent from 50.3 to $62.3 \mathrm{sq}$. cm. (table 1). The cardiac output was $9028 \mathrm{cc}$. per minute (table 2). Two hours after tincture of digitalis $3.7 \mathrm{cc}$. was injected the output fell to $1541 \mathrm{cc}$. per minute; $20 \frac{1}{2}$ hours afterward it decreased further to $1307 \mathrm{cc}$. The dog died during the following 24 hours before another estimation of cardiac output was made. In this animal the decrease in output was enormous (86 per cent). Death occurred probably due to this cause on the third day after the drug was given.

Mitral insufficiency was created in dog 90 on February 28, 1924. A soft systolic murmur was heard for some months after operation, but later it disappeared. Four years after operation the area of the heart was approximately the same as before operation ( 5 per cent increase) (table 1). The cardiac output was $1810 \mathrm{cc}$. (table 2, fig. 2). Tincture of digitalis $2.0 \mathrm{cc}$. was injected intravenously and $1.0 \mathrm{cc}$. subcutaneously. The output fell 3 hours afterward to 1395 cc. and 24 hours later still further to $488 \mathrm{cc}$. The dog died shortly after this estimation of cardiac output.

Summary. In 5 dogs the subjects of artificially enlarged hearts and in a sixth in which there was no enlargement, the administration of digitalis in doses believed to be therapeutic was followed by decreases in cardiac output ranging from 32.8 to 86 per cent (table 2, figs. 1 and 2). The maximum decrease having been reached in 2 to 24 hours, the cardiac output gradually returned toward normal. In three the experiments were repeated approximately 10 months after the first ones and on these occasions also, the cardiac output decreased.

The action of digitalis on the other measurements (size and excursion, and electrocardiogram) which were made may be summarized very briefly.

Effect of digitalis on the size of enlarged hearts. Dog 162 may serve 
as an example. On March 19, 1928, the area of the heart was $78.5 \mathrm{sq}$. $\mathrm{cm}$. (table 2). Digitalis was then administered and three hours later the area diminished to $62.7 \mathrm{sq} . \mathrm{cm}$., 79.8 per cent of the initial value. There was an increase 2 days later to $71.2 \mathrm{sq} . \mathrm{cm}$. or 90.7 per cent of the first measurement. Ten days later, on March 29, 1928, digitalis was again injected. The area of the heart at this time was $70.2 \mathrm{sq} . \mathrm{cm}$. (table 2, figs. 1 and 3). Three hours afterward the area decreased to $57.3 \mathrm{sq} . \mathrm{cm}$. or 81.6 per cent of the size before this injection. The area increased slightly to $60.6 \mathrm{sq} . \mathrm{cm} .24$ hours later, or 86.4 per cent. The size 4 days later increased still more to $63.8 \mathrm{sq}$. cm. or 90.9 per cent. On both occasions the size of the heart decreased within 24 hours, 20 and 18 per cent respectively. Then it gradually increased as the effect of digitalis wore off. This dog had been given digitalis 9 months before (table 2) and on this occasion also there was a decrease in size of 25.6 per cent.

The effect of digitalis in the other dogs was similar to that just described. Digitalis was given to dog 161 on two occasions (table 2), to dog 171 once (table 2), to dog 155 once (table 2), to dog 158 on three occasions (table 2) and to dog 90 once (table 2, fig. 2). The greatest decrease detected occurred sometimes at $2 \frac{1}{2}$ hours and at other times 24 hours after the injection of digitalis and varied in extent between 11 and 29 per cent. Decrease was followed by increase in size as the effect of digitalis diminished.

Effect of digitalis on ventricular contraction of enlarged hearts. On March 29, 1928 in $\operatorname{dog} 162$ the left ventricular excursion was $2.1 \mathrm{~mm}$. at the level of the 6th rib (table 2, figs. 1 and 4). Digitalis was then given. The left ventricular excursion 3 hours later was $3.7 \mathrm{~mm}$. At the end of the first day it was $3.8 \mathrm{~mm}$., and at the end of the fourth, it was $3.4 \mathrm{~mm}$. The right ventricular excursion increased from $3.6 \mathrm{~mm}$. to a maximum of $7.3 \mathrm{~mm}$. The maximum increase of the left ventricular excursion was accordingly 181 per cent and of the right 200 per cent. As the effect of digitalis wore off the excursions became small.

There are observations like these in 3 other dogs (table 2, fig. 2). All behaved alike. The increase in height of excursion of the left ventricle ranged between 16 and 81 per cent. Whenever right ventricular excursions could be measured, increases attaining 100 per cent were observed. In all cases, measurement was however not possible 
ALFRED E. COHN AND HAROLD J."STEWART

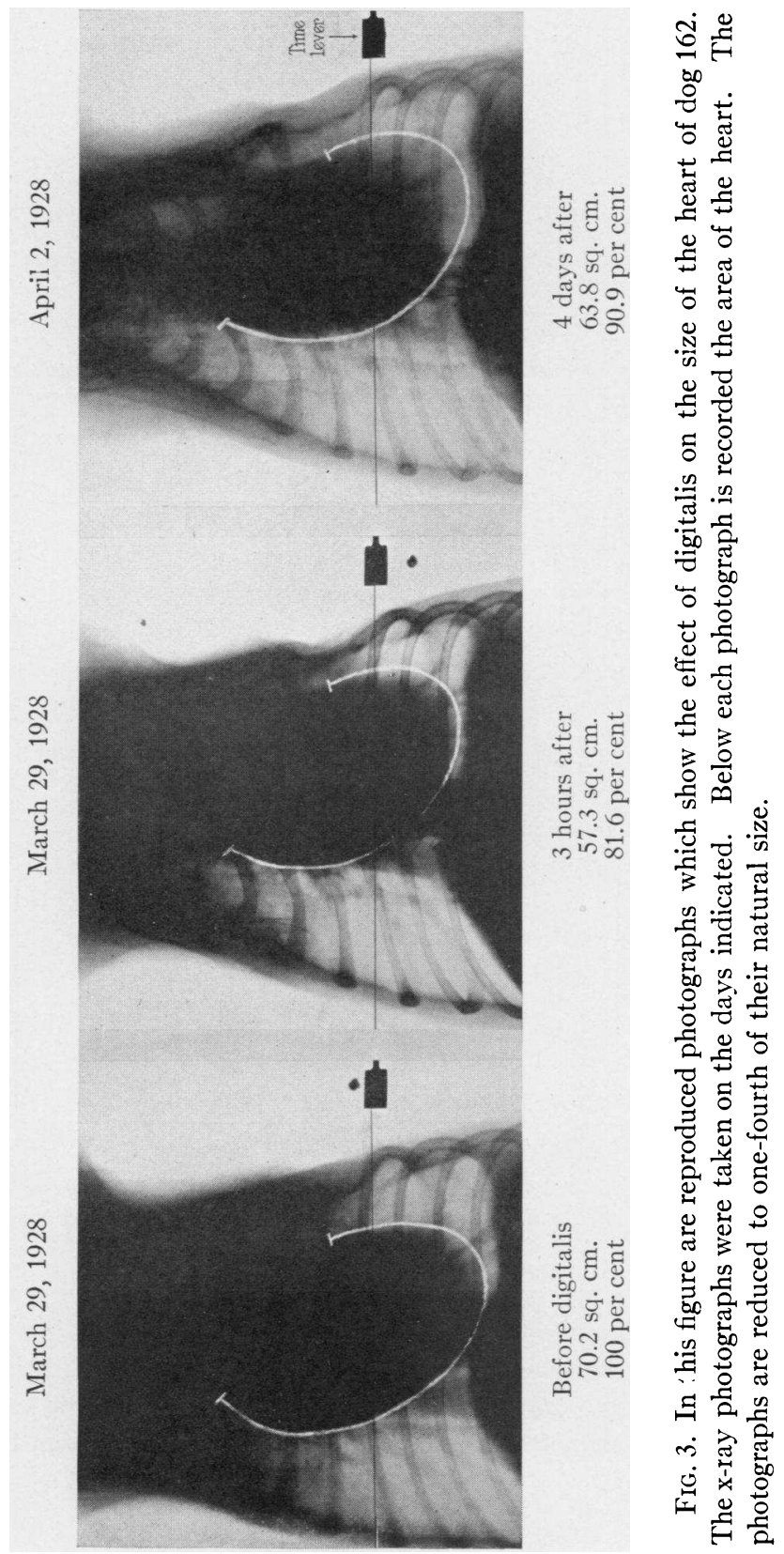


because for anatomical reasons (position of sternum or vertebral column) clear photographs of the excursions were not obtained.

Effect of digitalis on rate, conduction time and on the form of the electrocardiogram. Changes in the form of the T-wave were constantly found following the administration of digitalis (tables 2 and 3). The ventricular rate was sometimes increased, sometimes decreased and at other times unchanged. The conduction time was increased in 3

TABLE 3

Summary of effect of digitalis on the electrocardiograms of dogs with enlarged hearts

\begin{tabular}{|c|c|c|c|c|c|c|}
\hline $\begin{array}{c}\text { Dog } \\
\text { number }\end{array}$ & Date & $\begin{array}{l}\text { Ventricu- } \\
\text { lar rate }\end{array}$ & $\underset{\text { interval }}{\text { P-R }}$ & T-waves & $\begin{array}{l}\text { Abnormalities due to } \\
\text { digitalis }\end{array}$ & $\begin{array}{c}\text { Degree of } \\
\text { enlarge- } \\
\text { ment of } \\
\text { heart }\end{array}$ \\
\hline & & & & & & per cent \\
\hline 90 & March 26, 1928 & 0 & 0 & c & Vent. Par. Tach. & 5 \\
\hline \multirow[t]{3}{*}{158} & May 31,1927 & - & + & c & A. P. C. & 82 \\
\hline & June $\quad 9,1927$ & + & + & c & Vent. Par. Tach. & 82 \\
\hline & March 22, 1928 & + & + & c & Aur. Fib.; V. P. C. & 94 \\
\hline 155 & May 16,1927 & - & + & c & None & 18 \\
\hline \multirow[t]{2}{*}{161} & June $\quad 6,1927$ & - & 0 & c & None & 55 \\
\hline & March 27, 1928 & + & 0 & c & $\begin{array}{l}\text { Runs of Vent. Par. } \\
\text { Tach. }\end{array}$ & 77 \\
\hline \multirow[t]{3}{*}{162} & May 23,1927 & 0 & 0 & c & V.P. C. & 20 \\
\hline & March 19, 1928 & 0 & + & c & I-H. B. & 22 \\
\hline & March 29, 1928 & 0 & 0 & c & None & 22 \\
\hline 171 & June $\quad 7,1927$ & + & 0 & c & None & 24 \\
\hline
\end{tabular}

$\mathrm{c}=$ changed; $0=$ unchanged $+=$ increased; $-=$ decreased. Vent. Par. Tach. $=$ Ventricular paroxysmal tachycardia. A. P. C. $=$ Auricular premature contractions. Aur. fib. = Auricular fibrillation. V. P. C. $=$ Ventricular premature contractions. I-H. B. = Incomplete heart block.

FIG. 4. In this figure are reproduced photographs of the moving films obtained in the manner described in the preceding paper (Cohn and Stewart, 1928). Below each photograph are placed tracings of the original films which show the excursions made by the right and left ventricles respectively. When these photographs were taken the time marker was not working properly. The film was moving however, at a constant speed. The photographs are reduced to one-fourth of their natural size. 

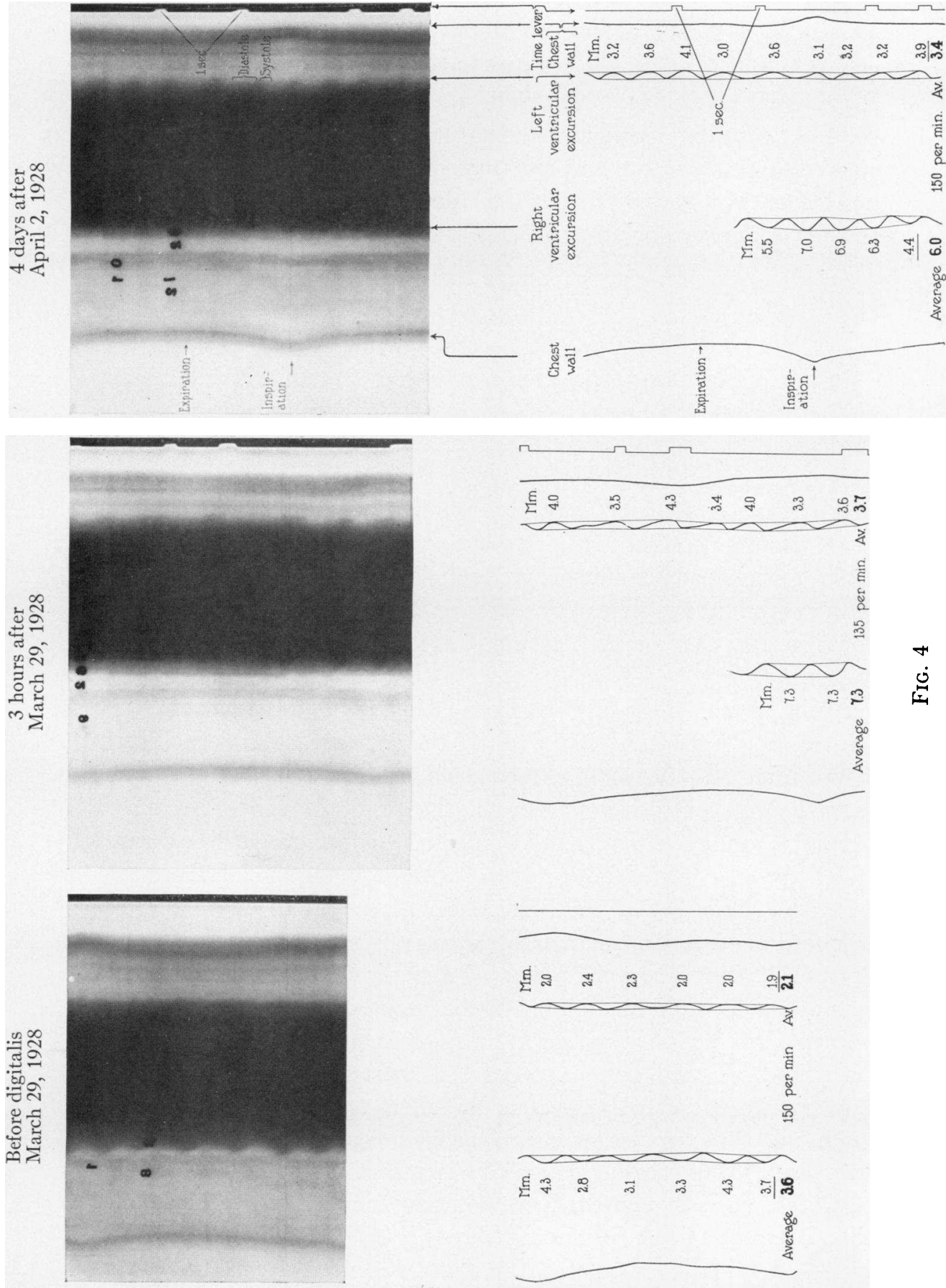
dogs (dogs 155, 158 and 162). Evidence of toxic action was manifested in the form of irregularity in all dogs except 155 and 171. Paroxysmal ventricular tachycardia was encountered in 3 dogs (dogs 90, 158 and 161). Auricular premature contractions were observed once (dog 158), ventricular premature contractions (without paroxysmal ventricular tachycardia) twice (dogs 158 and 162), incomplete heart block once (dog 162) and auricular fibrillation once (dog 158). These effects were all transient and occurred at the height of the action of digitalis.

\section{DISCUSSION}

In the light of these experiments it appears that the effect of giving digitalis results just as was the case in normal dogs in decreasing the cardiac output and the size of the heart and in increasing the height of ventricular excursions in dogs in which the hearts are enlarged but in which the signs of heart failure have not developed. Whether enlargement was due to dilatation or to hypertrophy or to both we do not know, for most of the animals are still alive. There can be no doubt however that at the time of observation they were in a state of compensation, for they ran on a treadmill as long and with as great ease as did normal dogs.

As in normal dogs, giving digitalis increased the tone of heart muscle, an effect which is reflected in the decreased size of the heart. The cardiac output was in consequence also decreased. Again as in normal dogs contraction increased, the result of which tended to increase cardiac output. And finally, the effect on cardiac output which depends upon the net result of the interaction of these two functions varied. For the first 24 hours the effect on tone overbalanced that on contraction so that cardiac output was uniformly decreased. But when the action of digitalis began to diminish, the rate at which it did so, differed in the various functions, so that the effect on contraction measured in terms of the height of the ventricular excursions exceeded the effect on tone, estimated in terms of the size of the heart, or persisted long after the effect upon it (tone) began to diminish. In such instances, the cardiac output returned to normal or overshot this mark, due to the increased extent of ventricular excursion, even though the heart sometimes continued to be smaller than it had been in the beginning ( $\operatorname{dog} 162$, (table 2 and fig. 1 ). 
There is a definite though no absolute correlation between cardiac size and cardiac output based on experience gained under the conditions of these experiments. If the cardiac areas obtained by measuring the stationary x-ray photographs of all dogs (column 15, table 2) are arranged in decreasing order of magnitude (fig. 5), the magnitudes being expressed as per cents of the initial values in each case, and if against each such measurement is plotted the cardiac output obtained at the time the measurement of area was made, also expressed as per

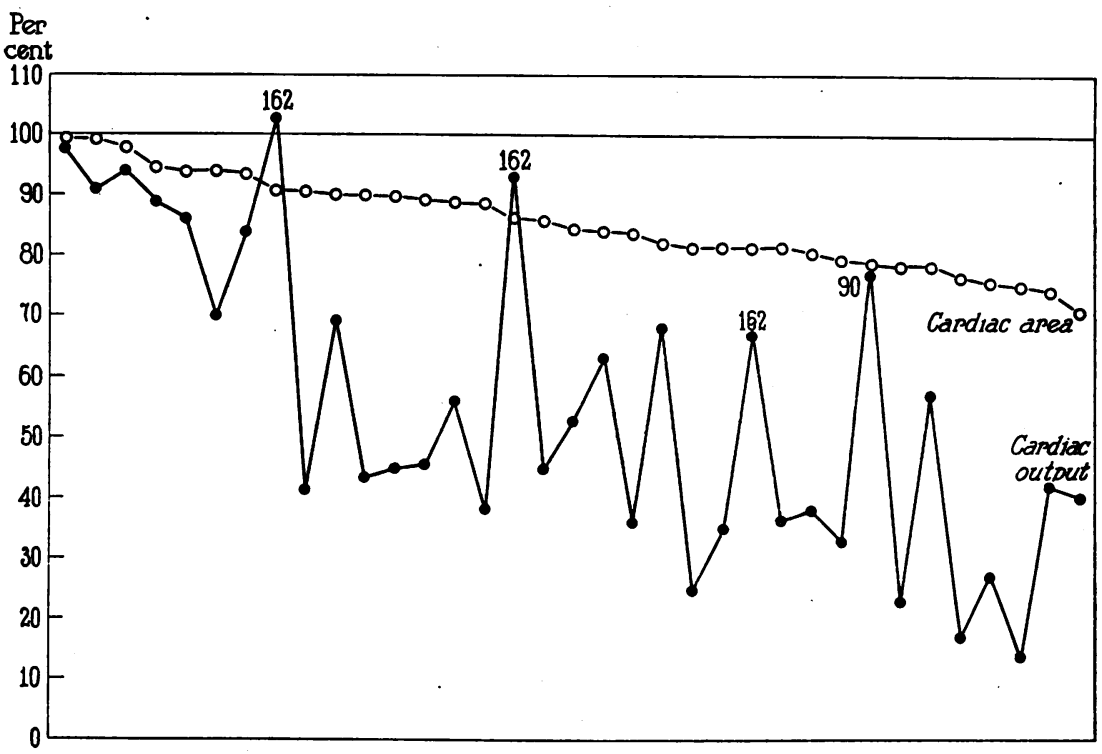

Fig. 5. This figure shows a correlation between cardiac size and cardiac output. For explanation see text.

cent of the original value, it becomes clear that, as the area of the heart decreases the volume output also decreases. There may be fluctuations, but the uniform tendency downward of the two curves is unmistakable. The curve of cardiac output decreases more rapidly than does that of the area of the heart, but this absence of parallelism depends on the fact that cardiac output is a cubic, while the heart area is a square measurement. It is obvious from a study of this figure that cardiac size is not the only factor involved. The high peaks require explanation. Clearly they interfere with the simple correlation of the 
two curves. We believe we are correct in referring the irregularities to the influence of ventricular contraction. Where the peaks occur, increase in the height of excursion was great enough to effect cardiac output; increase in excursion then overbalanced decrease in size and permitted an excess in output beyond that which would have been anticipated from the slope of the curve. All of this, as well as the origin of the blood responsible for the unlooked for results are discussed also in the preceding paper.

Two dogs (dogs 90 and 171, table 2) died following the administration of digitalis. The cardiac size was decreased in them as much as 25 per cent below the original measurement and the cardiac output 73 and 86 per cent respectively. Whether death was due to the inability of the small heart to pump enough blood to maintain life, or whether it was due to a toxic effect on the heart muscle we do not know. Paroxysmal ventricular tachycardia occurred in dog 90, but the normal rhythm continued to be present in dog 171 (table 2).

The changes in the electrocardiograms were on the whole more pronounced in these dogs than in the normal ones. An effect was found constantly in form of the T-waves (tables 2 and 3). Auriculoventricular conduction time increased in 3 dogs (dogs 155, 158 and 162) and on each of the 3 occasions on which digitalis was given to dog 158 (table 3). Abnormal rhythms (paroxysmal ventricular tachycardia, auricular fibrillation and incomplete heart block) as well as ectopic beats of auricular and ventricular origin were encountered. They were found perhaps more frequently in this group than in the normal dogs. That abnormal mechanisms are expected when digitalis is prescribed in large hearts oftener and rather than in normal ones is a consequence of clinical experience. But whether their occurrence is a result of size merely or whether both size and irregularity of action are dependent on a common underlying fault is not yet, so far as we know, understood.

The fact has been mentioned that dog 90 did not show cardiac enlargement (table 1). At the time of operation a soft systolic murmur appeared at the mitral area and persisted for several months. Then it disappeared leaving only a sharp first sound. Since cardiac enlargement did not develop in the absence of the murmur it is probable that no lesion of sufficient extent resulted from the operation. 
The case is reported since the dog had been subjected to the same operation as had the other dogs and serves as a control. It is important to decide for future guidance whether the presence of a murmur may be a certain sign of the presence of a lesion A report will be made later in connection with the study of the effect of artificial mitral insufficiency in dogs.

Three dogs (dogs 158, 161 and 162) were studied in May 1927 and again in March, 1928. In two (dogs 158 and 162) the oxygen consumption per minute, that is to say, the basal metabolism, remained remarkably constant (table 4). In the third dog (dog 161) the oxygen consumption was considerably less in 1928 than it had been. The estimates at both times are probably correct, for the dog lay quietly during the examinations; he was trained for sometime before each

TABLE 4

Comparison of the oxygen consumption of three dogs in 1927 and 1928

\begin{tabular}{c|c|c}
\hline \multirow{2}{*}{ Dog number } & \multicolumn{2}{|c}{ Oxygen consumption during control observations } \\
\cline { 2 - 3 } & 1927 & 1928 \\
\hline & cc. per minute & cc. per minute \\
158 & 128 & 126 \\
161 & 106 & 116 \\
& 154 & 104 \\
\hline
\end{tabular}

experiment; many measurements were made, all in substantial agreement, both in May, 1927, and again in March, 1928. The weight of the dog over this period of 10 months remained practically constant. We can suggest no explanation for this phenomenon.

We have shown then that enlarged hearts in dogs without heart failure respond to digitalis in the same manner as the hearts of normal dogs. This is the result one should expect. The question naturally arises whether these observations throw light on the way digitalis acts in heart failure in human disease. As is well known an effect of digitalis upon the size of the heart under these circumstances is not frequently demonstrable immediately after administration of the drug. After prolonged treatment the effect is often different; a decrease in size is frequently seen. With large doses, in normal cases, the effect on cardiac output comes on soon as Burwell, Neighbors and 
Regen (1927) showed. Though the heart does not become smaller, an influence on its size may nevertheless be demonstrated, as was shown by Levy (1923) in the case of lobar pneumonia. In this disease enlargement of the heart did not take place, or at least tended to occur less frequently if this drug was given. We have ourselves shown that in patients increase in ventricular excursions may take place after digitalis administration (Cohn and Stewart, 1924), even though no demonstrable change in the size of the heart can be seen in $\mathrm{x}$-ray photographs. If there is increase in contraction and no decrease in size of the heart the experiments which are now reported permit the inference that cardiac output increases. This may be the situation in heart failure in man, but of this there is no direct evidence. Should the mechanism of heart failure involve decrease in the volume output, as has until recently been generally believed to be the case, point would be given to what Starling (1918) described as the law of the heart. Starling believed, and showed in experiments, that when heart muscle fibers increased beyond a certain optimal length, decrease in output from the heart resulted. If the optimal, or a somewhat shorter length, were restored, output from the ventricles mounted. Heart failure may be a condition in which the fibers are longer than optimal; were digitalis able to restore them to a proper length, the requirement of the situation would be met. We have no information that contributes to an elucidation of this problem, but these considerations may explain why in the absence of heart failure, that is to say of edema, the results in our dogs so far as alterations in volume output are concerned are without specific value. The condition in them is simply not that of heart failure; they cannot be expected therefore to illustrate the mechanism which obtains in that condition.

\section{SUMMARY}

We have studied the effect of digitalis upon the cardiac output, cardiac size and ventricular contraction of dogs with enlarged hearts, but without signs of heart failure. We have found in them, as in normal dogs, that:

1. The size of the heart is decreased.

2. The extent of ventricular contractions is increased. 
3. The cardiac output which results is the net result of the effect of digitalis on the two underlying actions. Early, the effect on cardiac size predominates, so that the cardiac output diminishes. Later the effect on ventricular contraction may predominate, so that cardiac output reaches its original normal volume or even overshoots it, at a time when the size of the heart is still relatively small. The bearing of these observations upon the effect of digitalis in heart failure has been discussed.

\section{CONCLUSIONS}

The effect of digitalis on the hearts of dogs, whether normal in size or whether enlarged is the same. Caution attaches however to the use of the word enlarged; enlargement is not a simple matter. It still is necessary to learn whether enlargement resulting from mechanical embarrassment requires differentiation from enlargement due to underlying disease in which edema is a conspicuous phenomenon.

\section{BIBLIOGRAPHY}

Allen, D. S., and Graham, E. A., Jour. Amer. Med. Assoc., 1922, lxxix, 1028. Intracardiac Surgery-A New Method. Preliminary Report.

Burwell, C. S., Neighbors, D., and Regen, E. M., Jour. Clin. Invest., 1927, v, 125. The Effect of Digitalis upon the Output of the Heart in Normal Man.

Cohn, A. E., and Stewart, H. J., Jour. Clin. Invest., 1924, i, 97. Evidence that Digitalis Influences Contraction of the Heart in Man.

Cohn, A. E., and Stewart, H. J., Jour. Clin. Invest., 1928, vi, 53. The Relation Between Cardiac Size and Cardiac Output per Minute Following the Administration of Digitalis in Normal Dogs.

Fick, A., Verhandl. d. physikal. -med. Gesellsch. Würzb. 1870. N. F. ii. S. xvi. der Sitzungsber. Ueber die Messung des Blutquantums in der Herzventrikeln.

Levy, R. L., Arch. Int. Med., 1923, xxxii, 359. The Size of the Heart in Pneumonia. A Teleroentgenographic Study, with Observations on the Effect of Digitalis Therapy.

Starling, E. H., London, 1918. The Linacre Lecture on The Law of the Heart, given at Cambridge, 1915.

Stewart, H. J., Jour. Biol. Chem., 1925, lxii, 641. The Oxygen and Carbon Dioxide Contents of the Arterial and Mixed Venous Blood in Normal Intact Dogs.

Stewart, H. J., Experiments to be published. 